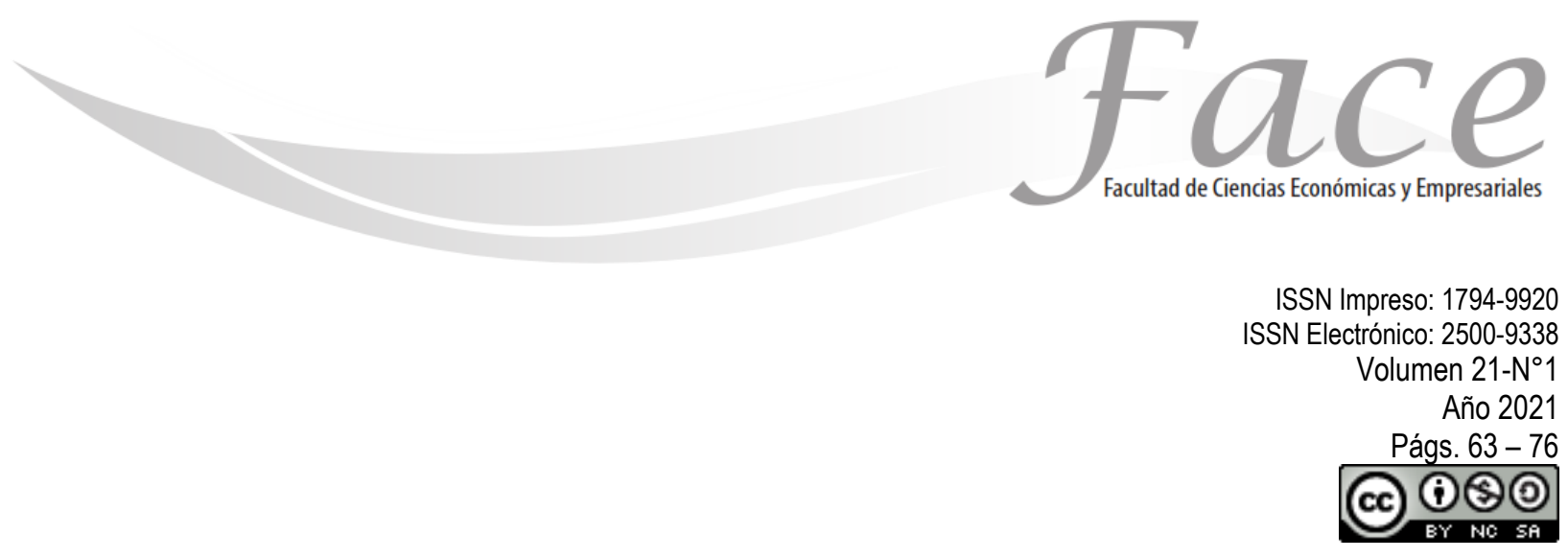

\title{
EVALUACIÓN DE LA ACCESIBILIDAD TURÍSTICA EN ESPACIOS CULTURALES: MUSEOS DE BOGOTÁ-COLOMBIA
}

\author{
Angie Tatiana Beltrán Murcia * \\ Enlace ORCID: https://orcid.org/0000-0002-9314-6070 \\ Jeffer Darío Buitrago Betancourt ** \\ Enlace ORCID: https://orcid.org/0000-0002-7247-7073 \\ Gilberto Stevan Moreno Mejía *** \\ Enlace ORCID: https://orcid.org/0000-0003-4698-2268
}

Fecha de Recepción: Noviembre 7 de 2020

Fecha de Aprobación: Febrero 10 de 2021

\section{Resumen:}

Superar las barreras de accesibilidad que impiden a las personas en condición de discapacidad física disfrutar de la oferta de servicios en espacios culturales puede llegar a convertirse en un reto gerencial y técnico, pues implica el diseño y puesta en marcha de ajustes y modificaciones de diversa índole, en especial cuando se trata de edificaciones patrimoniales. Por tal razón, resulta perentorio poder evaluar los aspectos que determinan la accesibilidad turística en espacios museales, con el fin de identificar falencias y oportunidades de mejora. De esta manera, en el presente artículo se describen los resultados obtenidos a partir del diseño y aplicación de una Matriz de Calificación de Accesibilidad Turística (MCAT), en cinco museos localizados en el centro de Bogotá, en la cual fueron incorporados 27 aspectos, agrupados en tres factores de accesibilidad: señalización, infraestructura y servicios.

Palabras clave: Turismo accesible, discapacidad física, museos, factores de accesibilidad

\footnotetext{
* Administradora Turística y Hotelera,- Fundación Universitaria Cafam-Colombia. Contacto: tbeltranudea@gmail.com

** Administrador de Empresas-Universidad Nacional de Colombia, Magíster en Medio Ambiente y Desarrollo y Doctor en Geografía-Universidad Autónoma de Barcelona - España, Contacto: jdbuitragob@gmail.com

${ }^{* \star *}$ Administrador Turístico y Hotelero. Contacto: stevanmejia52@gmail.com
} 


\title{
EVALUATION OF TOURIST ACCESSIBILITY IN CULTURAL SPACES: BOGOTÁ MUSEUMS- COLOMBIA
}

\begin{abstract}
:
Overcoming the accessibility barriers that prevent people with physical disabilities from enjoying the offer of services in cultural spaces can become a managerial and technical challenge, since it implies the design and implementation of adjustments and modifications of various kinds, especially when it comes to heritage buildings. For this reason, it is imperative to be able to evaluate the aspects that determine tourist accessibility in museum spaces, in order to identify shortcomings and opportunities for improvement. In this way, this article describes the results obtained from the design and application of a Tourist Accessibility Rating Matrix (MCAT), in five museums located in the center of Bogotá, in which 27 aspects were incorporated, grouped in three accessibility factors: signage, infrastructure and services.
\end{abstract}

Keywords: Accessible tourism, physical disability, museums, accessibility factors

\section{AVALIAÇÃO DA ACESSIBILIDADE TURÍSTICA EM ESPAÇOS CULTURAIS: MUSEUS DE BOGOTÁ-COLÔMBIA}

Resumo:

A superação das barreiras de acessibilidade que impedem as pessoas com deficiência física de usufruírem da oferta de serviços em espaços culturais pode constituir um desafio gerencial e técnico, uma vez que implica conceber e implementar adaptações e modificações de natureza diversa, nomeadamente no que diz respeito a edifícios patrimoniais. Por este motivo, é imprescindível ser capaz de avaliar os aspectos que determinam a acessibilidade turística nos espaços museológicos, de forma a identificar lacunas e oportunidades de melhoria. Desta forma, este artigo descreve os resultados obtidos a partir da concepção e aplicação de uma Matriz de Avaliação de Acessibilidade Turística (MCAT), em cinco museus localizados no centro de Bogotá, na qual foram incorporados 27 aspectos, agrupados em três fatores de acessibilidade: sinalização, infraestrutura e serviços.

Palavras-chave: Turismo acessível, deficiência física, museus, fatores de acessibilidade 


\section{INTRODUCCIÓN:}

La accesibilidad para personas con discapacidad física es un tema de gran relevancia, que amerita un tratamiento profundo, en la medida que se ha venido constituyendo en requisito primordial para garantizar la inclusión social, la igualdad de condiciones y el respeto a los derechos de circulación y locomoción. Es por esto que, durante las últimas décadas, la mayoría de instituciones y entidades del país han venido realizando esfuerzos por mejorar la calidad en el acceso al segmento de público en condición de discapacidad.

A pesar de los avances, aun hace falta mucho camino por recorrer y aspectos por determinar. Uno de ellos tiene que ver con el grado de accesibilidad en sitios urbanos de interés turístico cultural, específicamente en museos, galerías, jardines botánicos, parques recreativos y también temáticos. No obstante, realizar esta evaluación no es tarea fácil, pues requiere de un proceso en el cual deben confluir diferentes elementos y recursos a lo largo del tiempo.

Por tal razón, en el presente artículo se describe un conjunto de factores que, organizados bajo un esquema de matriz, pueden ser de gran utilidad para evaluar el grado de accesibilidad turística en sitios patrimonio cultural, específicamente en cinco museos localizados en la Zona de Interés Turístico del Centro Histórico de la ciudad Bogotá, los cuales son el Museo Militar, el Museo de la Independencia, el Museo Santa Clara, el Museo del Oro y la Casa de la Moneda.

Esta propuesta de factores está basada en la revisión de propuestas teóricas conceptuales, halladas en decretos, resoluciones, políticas y proyectos elaborados por la Alcaldía Mayor de Bogotá, el Instituto Distrital de Turismo (IDT), el Ministerio de Comercio, Industria y Turismo y la Organización Mundial del Turismo (OMT) y también en la opinión brindada por expertos, vinculados a estos museos del centro histórico de la ciudad.

Con base en esta revisión surgió la pregunta de investigación: ¿de qué manera es posible evaluar la accesibilidad turística en espacios culturales?, en consecuencia, se planteó como objetivo principal, la formulación de una propuesta de valoración de características de infraestructura y de servicios turísticos para personas en condición de discapacidad física, en cinco sitios de patrimonio cultural de la ciudad de Bogotá, bajo la premisa de que se trata de espacios de visita, donde se debe propender por la aplicación de los principios del turismo accesible.

Para lograr el objetivo planteado, fue empleada una metodología de tipo cualitativa, compuesta por dos procesos esenciales: el primero, la revisión de literatura referida a la política pública de discapacidad y la normativa de accesibilidad en Bogotá. El segundo proceso consistió en la consulta a personas expertas, que guardan algún tipo de vínculo con cada uno de los museos mencionados.

\section{MARCO TEÓRICO}

\section{Turismo accesible en museos}

Molina y Cànoves (2010), mencionan que la Organización Mundial del Turismo (OMT), relaciona por primera vez al sector del turismo con el ámbito de la accesibilidad en la Declaración de Manila de 1980, partiendo de reconocer que la actividad turística es un derecho fundamental y necesario para el desarrollo humano. 
Martínez y García (2015) mencionan que la

En líneas generales, el turismo accesible significa habilitar a las personas con dificultades de acceso, en términos de movilidad reducida, carencia de visión, discapacidad auditiva y cognitiva, las posibilidades de disfrutar de forma independiente, equitativa y digna, de los bienes, servicios turísticos en entornos con diseño universal (Darcy y Dickson, 2009 en Wiastuti, et al., 2018).

Como lo menciona Sánchez et al. (2020), citando a Guerrero Palma (2018), existen indicadores que evalúan la accesibilidad, pero desde la perspectiva de la normatividad arquitectónica que han de cumplir las edificaciones para eliminar las barreras que limitan el acceso, pero no para valorar la ampliación de posibilidades de disfrute de espacios culturales, por parte de turistas y visitantes.

En los últimos años se han publicado manuales técnicos que permiten a los gestores de espacios turísticos, tener unos lineamientos para encaminarse hacia el turismo accesible, entre los cuales se destacan el libro Turismo Accesible: hacia un turismo para todos, de Pérez y González (2003), las Recomendaciones de la OMT por un turismo accesible para todos (2014) y el Manual de turismo accesible para todos: Alianzas públicoprivadas y buenas prácticas, elaborado por la Fundación ACS y la OMT (Martínez y García, 2015).

Estos y otros documentos que han sido elaborado para promover las buenas prácticas en materia de accesibilidad turística, han aportado elementos clave para brindar mayores condiciones de igualdad a visitantes asiduos y turistas, en diferentes espacios de ocio, contemplación y recreación. principal diferencia entre turismo tradicional y turismo accesible es que este último está orientado a brindar a las personas en condición de discapacidad y movilidad reducida, la posibilidad de llevar a cabo sus actividades de manera independiente, haciendo uso de los diferentes productos y servicios turísticos. (Darcy, Cameron, Pegg, \& Packer, 2008).

En cuanto a la relación entre turismo accesible y museología, cabe mencionar que a pesar de que se trata de dos ámbitos de estudio y de gestión perfectamente diferenciados, durante las últimas décadas su tácito vínculo ha venido cobrando relevancia, por la inclusión progresiva de las infraestructuras patrimoniales y museísticas, en la oferta turística en las ciudades.

El fortalecimiento turístico de estos espacios culturales, ha hecho que su dinamización y proyección estén articulados con la promoción turística de las ciudades, para lo cual, la integración de públicos diversos, más que un lema publicitario, se constituye en un objetivo misional. Daza Corredor, A., Viloria Escobar, J., \& Miranda Terraza, L. (2018).

A pesar de la existencia de dicho vínculo, el volumen de investigaciones relacionadas con la interrelación entre los sistemas patrimonial y turístico está todavía en construcción y temas como la accesibilidad turística en espacios museísticos se encuentra prácticamente en estado incipiente (Arrieta, 2012)

Como lo mencionan Fernández y Moral (2017), hoy en día son numerosos los museos que han venido incorporando en sus planes de acción, medidas en materia de accesibilidad, promoviendo la eliminación de barreras como estrategia para asegurar la mayor accesibilidad posible, a las personas en condición de discapacidad física, a los recursos turísticoculturales. 
A nivel normativo se destacan algunas leyes que durante las últimas décadas se han venido implementando en Colombia, las cuales han ido en consonancia con las políticas trazadas por los últimos gobiernos. Espitia y Padilla (2015) mencionan que además de la Constitución Política de 1991, la Ley 12 de 1987, la Ley 361 de 1997, el Decreto 1660 de 2003, el Decreto 1538 de 2005 y las normas técnicas colombianas (NTC), han establecido unas pautas de actuación en lo referente a la accesibilidad de personas en situación de discapacidad física.

En el año 2009, el gobierno nacional de Colombia, formuló la Política de Turismo Social bajo el eslogan "Hacia un turismo accesible e incluyente para todos los colombianos", elaborado por el Ministerio de Comercio, Industria y Turismo (Asociación Colombia de Facultades de Administración [ASCOLFA], 2015). Esta política fue diseñada con el objetivo de "facilitar el acceso de todos los colombianos al turismo (...), otorgando prioridad a aquellos segmentos de población con menores posibilidades de disfrute del mismo, tales como personas con discapacidad o de escasos recursos económicos, adultos mayores y jóvenes" (Ministerio de Comercio, Industria y Turismo, 2009, p. 21).

Una vez se establecen los lineamientos nacionales, se formulan en la ciudad de Bogotá los Protocolos de Servicio para el Turismo Accesible de Turistas y Visitantes Jóvenes, Adultos Mayores y Personas en Situación de Discapacidad, elaborado por la Alcaldía Local de Teusaquillo, el Instituto Distrital de Turismo y la Universidad Nacional de Colombia (2011). Este documento explica las relaciones, atenciones, precauciones, recomendaciones y procedimientos auxiliares que se deben tener con las personas en situación de discapacidad física, además de requisitos de formación, habilidades y competencias con las que debería contar el personal que presta el servicio.

Tomando en cuenta algunos de los aspectos consignados en dicho protocolo, hacia el año 2012, el IDT diseñó el Proyecto 0740: Bogotá ciudad turística para el disfrute de todos, con el objetivo de posicionar a Bogotá como destino turístico incluyente y sostenible; a través de la adecuación y mejoramiento de la calidad del destino, así como de la promoción y divulgación de su oferta turística para el disfrute de todos (IDT, 2012).

Como antecedentes de estudios sobre la accesibilidad en museos colombianos se encuentra un Diagnóstico del sector museal colombiano, realizado por el Museo Nacional de Colombia en el año 2014, donde se menciona que prácticamente de una muestra de 166 entidades analizadas en el país, ninguna cuenta con mecanismos de accesibilidad. "Solo un número muy bajo ha avanzado en alternativas como sanitarios adaptados, rampas de acceso, barandas, ascensor 0 elevador adaptado y señalización en braille" (Museo Nacional de Colombia, 2014, p. 29).

Estos avances físicos han ido de la mano con la formulación de documentos guía, denominados manuales de buenas prácticas, los cuales recogen los procedimientos que han de tener en cuenta los gestores de entidades museales para la implementación de procedimientos que contribuyan a ampliar las posibilidades de acceso a las personas en condición de discapacidad física. Uno de los que se ha publicado hasta el momento en Colombia, ha sido el Manual de buenas prácticas de accesibilidad del Museo de Arte Contemporáneo de Bogotá (Samboní, 2015).

\section{METODOLOGÍA:}

La metodología empleada en la investigación fue de tipo cualitativa exploratoria y estuvo compuesta por tres fases: la primera, el diseño del instrumento para evaluar la accesibilidad turística en espacios museales, la segunda, la selección de los museos donde fue aplicado el instrumento, y la tercera, el juicio de expertos. A continuación, se describen con mayor detalle cada una de estas fases. 
1. Diseño del instrumento de calificación: De acuerdo con Alvarado et al. (1994), citados por Corral (2009), "un instrumento es el mecanismo que usa el investigador para recolectar y registrar la información" (229). Para el caso de la investigación realizada, el instrumento diseñado y utilizado fue la Matriz de Calificación de Accesibilidad Turística (en adelante MCAT), la cual fue elaborada teniendo en cuenta las condiciones que se deben garantizar para el disfrute de los visitantes y turistas que asisten a espacios museales.

En ese sentido, se tuvieron en cuenta las siguientes normas y documentos: Normas Técnicas Colombianas NTC 6047, NTC 4141, NTC 5610 y NTC 6002, Decreto 1660 de 2003, Decreto 197 de 2014 de la Alcaldía Mayor de Bogotá, Política de Turismo Social de Colombia (2009), Política Pública Nacional de Discapacidad e Inclusión Social (2013), Ley Estatutaria 1618 de 2013,
Programa "Bogotá Destino Turístico Accesible" del Instituto Distrital de Turismo, Lineamientos Arquitectónicos y de Accesibilidad al Medio Físico en Puntos de Servicio al Ciudadano de la Veeduría Distrital (2018), Declaración sobre la Facilitación de los Desplazamiento Turísticos de la OMT (2009), Guía de Accesibilidad en Museos del Ministerio de Educación, Cultura, Ciencia y Tecnología de Argentina (2018).

La estructura de dicha matriz permitió incluir y calificar tres factores clave de la accesibilidad turística, a saber: señalización, infraestructura y servicios. Cada uno de estos factores estuvo asociado con unos criterios e ítems, los cuales brindaban la posibilidad de calificación bajo una escala compuesta por tres grados de valoración: incumplimiento, cumplimiento aceptable y cumplimiento óptimo (ver tabla 1).

Tabla $N^{\circ}$ 1. Estructura de la Matriz de Calificación de Accesibilidad Turística

\begin{tabular}{|c|c|c|c|c|}
\hline Criterios & Ítems & $\begin{array}{l}\text { Incumple } \\
\text { (Valor cero) }\end{array}$ & $\begin{array}{l}\text { Cumplmto } \\
\text { aceptable } \\
\text { (valor 1) }\end{array}$ & $\begin{array}{c}\text { Cumplmto } \\
\text { óptimo } \\
\text { (valor 2) }\end{array}$ \\
\hline Internos & $\begin{array}{l}\text { - Señales referenciales } \\
\text { - Estado de las señales referenciales }\end{array}$ & \multirow{2}{*}{\multicolumn{3}{|c|}{ Factor señalización }} \\
\hline Externos & $\begin{array}{l}\text { - } \quad \text { Paneles de información para diversos públicos } \\
\text { - Información en corredores } \\
\text { - Información en salas de exposición } \\
\text { - Señales de dirección } \\
\text { - } \quad \text { Coincidencia de señales con áreas } \\
\text { - } \quad \text { Altura de piezas de colección } \\
\text { - Clara descripción de piezas en la descripción de piezas } \\
\text { - Símbolo internacional de Accesibilidad }\end{array}$ & & & \\
\hline Internos & $\begin{array}{ll}\text { - } & \text { Presencia de rampas y pasamanos } \\
\text { - } & \text { Entrada con dimensiones adecuadas } \\
\end{array}$ & \multirow{2}{*}{\multicolumn{3}{|c|}{ Factor infraestructura }} \\
\hline Externos & $\begin{array}{ll}\text { - } & \text { Piso con superficie lisa y antideslizante } \\
\text { - } & \text { Corredor con dimensiones adecuadas } \\
\text { - } & \text { Espacios de exposición adecuados } \\
\text { - } & \text { Presencia de rampas y pasamanos } \\
\text { - } & \text { Presencia de ascensor } \\
\text { - } & \text { Acceso al ascensor libre de obstáculos } \\
\text { - } & \text { Dimensiones adecuadas del ascensor } \\
\text { - } & \text { Baños adecuados } \\
\end{array}$ & & & \\
\hline Internos & $\begin{array}{ll}\text { - } & \text { Personal de seguridad } \\
\text { - } & \text { Personal capacitado en accesibilidad turística } \\
\text { - } & \text { Personal capacitado en atención a diversos tipos de públicos } \\
\text { - } & \text { Accesibilidad de la información museográfica y orientativa } \\
\text { - } & \text { Ayudas tecnológicas para diversos públicos } \\
\text { - } & \text { Elementos interactivos para diversos públicos } \\
\end{array}$ & \multicolumn{3}{|c|}{ Factor servicios } \\
\hline
\end{tabular}

Fuente: Elaboración propia 
Con el propósito de facilitar la calificación otorgada por expertos, como se explica en el tercer apartado, los factores de señalización e infraestructura fueron desagregados en dos tipos de criterios. El primer de ellos fue el interno, referido a las acciones y estrategias implementadas al interior de las instalaciones de cada museo. En contraposición, el segundo tipo de criterios fue el externo, que estuvo referido a la prolongación de elementos para atraer o facilitar el acceso de visitantes, desde el exterior de las instalaciones.

Para el caso del factor de señalización, los criterios internos estuvieron compuestos por 2 ítems y los externos por 9 ítems, para un total de 11. En cuanto al factor de infraestructura, los criterios internos estuvieron compuestos por 2 ítems y los externos por 8 ítems, conformando un total de 10 . Adicionalmente, el factor de servicios fue desagregado en 6 ítems, los cuales fueron todos de tipo interno (ver tabla 1).

Todos los 27 ítems fueron sometidos a juicio de los expertos, quienes debían asignar una calificación cuantitativa en escala de 0 a 2 , donde cero (0) correspondía al incumplimiento del ítem evaluado; uno (1) indicaba el cumplimiento aceptable de las condiciones de accesibilidad de manera deficiente, y finalmente 2, que indicaba el cumplimiento óptimo de las condiciones de accesibilidad turística para atender las necesidades de personas en condición de discapacidad física. Cabe mencionar que en el formato de la MCAT remitido a los expertos, se incluyó una columna de observaciones, en la cual ellos podían agregar algún comentario al frente del valor numérico asignado para justificar, explicar o respaldar la calificación otorgada.
2. Selección de los museos: Esta selección se llevó a cabo mediante la técnica de muestreo no probabilístico por conveniencia (Otzen y Manterola, 2017), fundamentada en dos criterios principales: la relevancia histórica y la proximidad geográfica de los espacios museales, debido a que se encuentran ubicados dentro de la Localidad de la Candelaria de Bogotá, la cual, a su vez, está situada en el centro oriente de la ciudad.

La Candelaria es uno de los principales atractivos turísticos, debido a que cuenta con un importante acervo patrimonial de la ciudad, "que incluye inmuebles de interés cultural del nivel distrital y nacional, así como de una amplia oferta cultural, representada principalmente en museos, galerías de arte, teatros y fundaciones artísticas, entre otras" (Sandoval, 2015).

A continuación, se presenta una breve reseña de cada uno de los museos que fueron analizados, con la metodología de investigación propuesta.

- La Casa de la Moneda: se encuentra localizada en el centro de Bogotá, frente a la Biblioteca Luis Ángel Arango. Fue construida durante el gobierno del Virrey Solís en 1753 y en la actualidad cuenta con exposiciones donde se destacan los procesos relacionados con la producción de monedas y billetes a lo largo de la historia de Colombia (Bustos y Rodríguez, 2009).

- Museo de la Independencia: Funciona en la edificación colonial de finales del siglo $\mathrm{XVI}$ ubicada en la esquina nororiental de la Plaza de Bolívar, en el centro de Bogotá (Atehortua, 2010 en Vargas, 2016). "Es una de las edificaciones más importantes de la historia colombiana, donde tuvo lugar la famosa reyerta del florero de Llorente del 20 de julio de 1810, considerada como el origen de la nación independiente según la historia patria" (Atehortua, 2010 en Vargas, 2016, p.80). 
- Museo Militar de Colombia: Se encuentra localizado en el centro histórico de Bogotá y está dedicado a resaltar la historia de las fuerzas militares del país. Funciona en un antiguo edificio, cuya fachada se caracteriza por combinar el estilo ornamental con el art deco y el art nouveau (Rojas, 2014).

- Museo Santa Clara: "Abrió sus puertas al público en 1983, en el recinto de lo que fue la iglesia y el convento de Santa Clara, terminados en 1647" (García, 2018, p.1). Posee características barrocas, que interactúan con algunos elementos renacentistas y con aspectos mudéjares hallados en la pintura mural, las celosías y las bóvedas (Ministerio de Cultura de Colombia, 2020).

- Museo del Oro: Fue creado en el año 1939 por el Banco de la República de Colombia y actualmente se encuentra localizado en el costado oriental del Parque Santander en el centro de Bogotá. Constituye la colección de orfebrería más importante del país y durante las últimas décadas se ha convertido en uno de los principales atractivos turísticos y culturales de Bogotá (Bautista, 2012).

3. Juicio de expertos: Con base en dos experiencias de validación, se emplea el juicio de expertos para la calificación de los atributos que poseen los museos seleccionados, en términos de accesibilidad turística. La primera experiencia es la de Escobar y Cuervo (2008) quienes, a partir de la validación de contenidos, desarrollada por autores como Ding y Hershberger (2002), Utkin (2005), Skjong y Wentworht (2000), y Arquer (1995), plantean un procedimiento compuesto por siete pasos, para llevar a cabo la toma de opinión de los expertos y la respectiva organización de la información resultante. Dichos pasos son los siguientes:

- Definir el objetivo del juicio de expertos
- Selección de los jueces

- Explicitar tanto las dimensiones como los indicadores que está midiendo cada uno de los ítems

- Especificar el objetivo de la calificación

- Establecer los pesos diferenciales de las dimensiones de la calificación

- Diseño de planillas

- Analizar la concordancia entre juicios

La segunda experiencia tomada como referente en esta investigación, fue la de Galicia et al. (2017), quienes diseñaron una herramienta virtual para validar el contenido de instrumentos de investigación, con base en la opinión emitida por académicos que participaron en el tema abordado.

A partir de estas dos experiencias, se llevó a cabo la toma de opinión de personas con conocimientos sobre museología y con algún grado de experticia en gestión del patrimonio cultural. Otro de los requisitos básicos era el conocimiento que debían tener estas personas acerca de cada uno de los museos seleccionados, ya fuera por algún vínculo laboral contraído o porque en algún momento realizaron estudios o publicaciones referidas a alguno de estos espacios.

Con base en estos aspectos, fueron contactados por vía telefónica cuatro expertos, a quienes les fue explicado los objetivos de la investigación y la importancia de su participación. Afortunadamente los cuatro expertos aceptaron participar, con lo cual la consulta para la calificación se hizo de manera virtual, a través del diligenciamiento de un formulario digital remitido por correo electrónico. 


\section{RESULTADOS:}

Con base en la calificación realizada por parte de los expertos, empleando la Matriz de Calificación de Accesibilidad Turística (MCAT), en lo concerniente a la variable de señalización fue posible evaluar un total de 11 ítems, divididos en los dos criterios abordados (interno y externo), a partir de lo cual se pudo identificar lo siguiente:

Los expertos indicaron que tres de los cinco museos analizados cuentan con señales referenciales, las cuales facilitan la llegada del visitante. Mencionan que dichas señales son legibles, fáciles de entender y se encuentran en buen estado, elementos totalmente indispensables para el goce integral de la visita, por parte de cualquier persona que desee asistir a estos lugares. En contraposición, el hecho de que dos de los museos analizados no cuenten con estos elementos, indica que hay una limitación a la accesibilidad, pero, en cualquier caso, uno de los expertos advierte que, de acuerdo con su conocimiento, esta señalización se encuentra en fase de diseño.

Con respecto a la colocación de paneles de información en la entrada de los museos analizados, los expertos coinciden en que solo uno de estos espacios cuenta con este dispositivo para brindar información clara y orientar el ingreso de los visitantes. Desde esta perspectiva, tres de los museos abordados no brindan las facilidades para hacer más accesibles los espacios internos y ayudar a organizar el recorrido al turista 0 visitante, de manera autónoma e independiente.

Un aspecto a destacar, a partir de las opiniones emitidas por los expertos, es que a diferencia de lo que ocurre con la zona de entrada, en los pasillos y salas de exposición la situación cambia notablemente, pues dichos espacios cuentan con información legible y de fácil visualización. En todo caso, advierten que algunos de los museos estudiados mantienen avisos y dispositivos a una altura no adecuada para personas con movilidad reducida, carecen de audioguías y de señalización en braille.

Siguiendo con la señalización, en los cinco museos analizados, los contenidos informativos son adecuados y facilitan la orientación al turista 0 visitante, pues según la opinión de los expertos, las salidas de emergencia, la ubicación de baños $y$ de servicios complementarios, resultan accesibles con facilidad, lo cual contribuye a brindar una mejor experiencia para todos los visitantes.

Con respecto a los elementos de información y piezas museográficas que se encuentran en corredores y áreas adyacentes a las salas de exposición, los expertos mencionan que tres de los museos analizados han dispuesto estos elementos a una altura adecuada para personas como movilidad reducida, aspecto que resulta relevante y primordial para facilitar la orientación de los turistas y visitantes. Agregan los expertos que el acceso a estos elementos es el adecuado, especialmente en aquellos museos que tienen escalones, pues este aspecto ha sido salvado mediante la implementación de rampas.

Otro de los aspectos favorables con el que cuentan los museos analizados, de acuerdo con la opinión de los expertos, es la descripción de las colecciones museográficas, pues presentan textos e imágenes cognitivamente accesibles, que resultan legibles y agradables de leer por el tipo de tipografía y pictografía usadas. Esto demuestra, como bien lo señalan ellos, que durante los últimos años ha habido un esfuerzo y compromiso por parte de las administraciones y gestores de estos espacios por implementar este tipo de medidas que claramente contribuyen a mejorar la accesibilidad, pero también se convierten en una estrategia de diferenciación y de comunicación museográfica.

Un aspecto sobre el cual hay que continuar coordinando esfuerzos, es en el de poder ajustar la señalización de estos museos a la normatividad que acompaña el Símbolo Internacional de 
Accesibilidad, de manera que sea posible mejorar significativamente la experiencia del segmento de turistas y visitantes en condición de discapacidad física, puesto que señales de este tipo, contienen colores y símbolos representativos, que transmiten la idea de inclusión y facilitan la orientación en espacios complementarios como estacionamientos, entradas, elevadores, sanitarios, áreas de servicio, etc.

Por otra parte, en relación con el factor infraestructura, donde fueron puestos a consideración 10 ítems, categorizados en criterios internos y externos, se pudo identificar lo siguiente:

De los cinco museos estudiados, tres de ellos cuentan con escalones en la entrada, aspecto que ha sido salvado con la colocación de rampas para facilitar el ingreso de personas en condición de discapacidad física. Estas rampas cuentan con pasamanos a ambos lados, que no solo facilitan la protección del turista o visitante, sino también favorecen la impulsión y apoyo para personas que cuentan con dispositivos de asistencia.

Los expertos consultados coinciden en otorgar una calificación de aceptable a tres de los cinco museos abordados, argumentando que disponen de un suelo adecuado para la movilidad, compuesto por materiales que permiten contar con una superficie lisa, que facilita el desplazamiento por los diferentes espacios internos. De manera complementaria, de acuerdo con su criterio, los otros dos museos analizados poseen piso de textura en sus salas de exposición, compuesto por ladrillo rústico, que en algunos puntos presenta imperfectos y deformaciones, lo cual puede llegar a representar algún tipo de dificultad en la movilidad, especialmente para aquellas personas que hacen uso de dispositivos de asistencia en su desplazamiento.

En cuanto a la dimensión de los pasillos y corredores, los expertos consideran que tres de los cinco museos cuentan con el ancho adecuado en este tipo de espacios, lo cual facilita la circulación de personas con dispositivos de asistencia sin problema alguno. Adicionalmente, algunos de los expertos consultados coinciden en señalar la estrechez de los pasillos que se evidencia en dos de los cinco museos analizados y la dificultad de poder ampliarlos, debido a que se trata de una construcción de estilo colonial y de carácter patrimonial.

Otro de los temas consultados con los expertos fue el de las dimensiones físicas de las salas de exposición con las que cuentan los museos abordados. Todos ellos coinciden en otorgar una calificación que demuestra que estos espacios son adecuados para la movilidad de la población en condiciones de discapacidad física. De todas maneras, uno de los expertos llama la atención sobre la necesidad de que algunos de los museos analizados tengan la precaución de no ubicar piezas y elementos museográficos en el centro de las salas, que puedan llegar a interferir con la libre circulación en el espacio.

En algunas entradas a las salas de exposición se evidencia la presencia de escalones, los cuales han sido salvados con la colocación de rampas; no obstante, de acuerdo con la opinión de los expertos consultados, en dos de los museos abordados, estos elementos arquitectónicos no cumplen enteramente con las medidas de seguridad establecidas, pues carecen de pasamanos o bandas antideslizantes, lo cual puede constituir un factor de riesgo para personas en condición de discapacidad física.

En relación con las dimensiones de los ascensores y la habilitación de accesos adecuados para su abordaje, los expertos coincidieron en otorgar una calificación de aceptable para el caso de tres de los museos analizados, mientras que para los otros dos museos, aclararon que uno de ellos no requiere ascensor, mientras que el otro, aunque sí lo requiere, no cumple con los aspectos mencionados, debido a que el ascensor existente no se encuentra en funcionamiento, además fue posible detectar que el espacio disponible antes 
de su ingreso es reducido y dificulta el acceso a este.

Con respecto a la adecuación de baños para los turistas y visitantes, los expertos asignaron una calificación de cumplimiento aceptable para los cinco museos y dos de ellos justificaron su calificación afirmando que, en uno de estos museos, se han presentado quejas acerca de las condiciones estructurales de los pasamanos y barras de apoyo. En el mismo sentido, el experto mencionó que ha habido comentarios de turistas y visitantes, señalando que la grifería no se encuentra a una altura adecuada.

Por otra parte, en relación con el factor Servicios, donde fueron puestos a consideración 6 ítems con criterio interno, se pudo identificar lo siguiente:

En los ítems referidos a presencia de personal de seguridad y personal capacitado, los cinco museos recibieron una calificación alta por parte de los expertos consultados, lo cual demuestra que ha habido un interés por vincular personal cualificado para prestar los servicios de conservación y difusión museológica, así como también para brindar la atención adecuada a turistas y visitantes. Adicionalmente, dos de los expertos sugieren la necesidad de promover y ampliar la inclusión laboral de personas en condición de discapacidad, no solo física sino también cognitiva en los cuatro museos estudiados.

En cuanto a la accesibilidad de la información, ésta estuvo referida a la manera como se propicia la interacción comunicativa al interior de los museos, a través de la disposición de elementos y formatos de mediación tales como guías personalizadas, audioguías, medios escritos y visuales. Para este caso, los expertos consultados otorgaron una calificación de aceptable para los cinco museos, argumentando que, si bien las guías personalizadas y la difusión que se realiza a través de medios impresos es destacable, hace falta una mayor producción de contenidos en medios audiovisuales y digitales, tales como realidad virtual, realidad aumentada, interacción digital y otras tecnologías, que permitan brindar experiencias inmersivas de manera remota.

Destacan los expertos las condiciones actuales de tres de los museos analizados, con respecto a los esfuerzos que han realizado sus directivas por implementar renovaciones museográficas a través de la digitalización de colecciones y la incorporación de elementos tecnológicos en salas de exposición, aspectos que favorecen la accesibilidad de sus contenidos a diversos públicos.

De acuerdo con los comentarios agregados por parte de dos expertos consultados, a pesar que uno de los museos cuenta con elementos tecnológicos para facilitar la interacción con los contenidos museográficos, estos no están enteramente accesibles al segmento de público en condición de discapacidad física, pues su alcance es limitado, especialmente para personas con movilidad reducida o que usan dispositivos de asistencia para su desplazamiento.

\section{CONCLUSIONES}

Con base en la investigación realizada, fue posible priorizar 27 aspectos (ítems) organizados bajo la Matriz de Calificación de Accesibilidad Turística (MCAT), los cuales permitieron evaluar los factores de señalización, infraestructura y servicios, para personas en condición de discapacidad física en cinco museos de Bogotá.

Debido a la importancia turística que han venido teniendo los museos Casa de La Moneda, Independencia, Militar, Santa Clara y del Oro en la ciudad de Bogotá, resultó pertinente llevar a cabo el diseño y aplicación de la Matriz de Calificación de Accesibilidad Turística (MCAT), a partir de la consulta a expertos conocedores de estos museos o que guardan algún tipo de vínculo con dichos espacios culturales. 
En términos de señalización y de comunicación de contenidos museográficos, existe un contraste entre las áreas internas y externas de los museos analizados, pues de acuerdo con la opinión de los expertos, mientras que en la mayoría de salas de exposiciones existen mecanismos y dispositivos que facilitan la accesibilidad a personas en condición de discapacidad física, en los halls de entrada y vestíbulos de la mayoría de estos museos, existen deficiencias en la señalización y comunicación orientativa para ayudar a organizar el recorrido al turista o visitante, de manera autónoma e independiente.

En términos de infraestructura, aunque la mayoría de las edificaciones de los museos analizados son de carácter patrimonial, en opinión de los expertos consultados, sus cuerpos directivos han venido realizando ingentes esfuerzos para poder adecuar estos espacios culturales a las normas de accesibilidad para personas en condición de discapacidad física, lo cual se evidencia con los avances en la implementación de rampas, ascensores, adecuación de pisos, ampliación de entradas, pasillos y vestíbulos, así como en la dotación de mobiliario tanto en las salas de exposiciones como en los lugares de servicios complementarios como baños, cafeterías y tiendas de souvenir.

A pesar de este importante avance, también es preciso mencionar que dentro de los comentarios hechos por parte de los expertos en cada uno de los ítems de la MCAT, se señala la necesidad de incorporar mejoras en algunos aspectos puntuales como el reforzamiento de pasamanos y soportes de apoyo en los baños de algunos de los museos analizados, la ampliación de zonas de acceso a los ascensores, reducción de altura en algunos soportes museográficos y la colocación de bandas antideslizantes en algunas rampas ubicadas tanto al interior como al exterior de estos museos.

Las calificaciones otorgadas por los expertos en el factor Servicios, reflejan un alto cumplimiento debido al destacado desempeño de los profesionales encargados de los temas de conservación y difusión museológica, así como también del personal de seguridad y servicios generales, por la adecuada atención que brindan a los diferentes tipos de públicos que acuden a estos espacios culturales.

Los otros dos aspectos que fueron evaluados en el factor Servicios fue el del acceso a la información y el del uso de tecnologías al interior de los museos para brindar mejores experiencias a los turistas y visitantes. Al respecto, es importante mencionar que, si bien en ambos aspectos ha habido grandes avances, hace falta incrementar la producción de contenidos digitales, para propiciar una mayor interacción in situ y también desde accesos remotos. Adicionalmente, en cuanto al uso de tecnologías, se hace necesario mejorar la adaptabilidad de estas a la diversidad de condicionamientos físicos 0 sensoriales que presentan algunos turistas $y$ visitantes.

De acuerdo con los resultados obtenidos, es posible concluir que resulta estratégico contar con instrumentos que permitan evaluar el grado de accesibilidad turística para personas en condición de discapacidad física, con el fin de incorporar mejoras en la prestación de los servicios brindados por los museos a este segmento del público, bajo condiciones igualitarias de acceso.

\section{REFERENCIAS:}

Alvarado, E., Canales, F. y Pineda, E. (1994). Metodología de la Investigación ( $2^{\mathrm{a}}$ ed.). Washington D.C: Organización Panamericana de la Salud.

Arrieta, I. (2012). Museos y turismo: expectativas y realidades. Bilbao: Servicio Editorial de la Universidad del País Vasco.

Asociación Colombia de Facultades de Administración [ASCOLFA], (2015). Compilación de ponencias presentadas 
EVALUACIÓN DE LA ACCESIBILIDAD TURÍSTICA EN ESPACIOS CULTURALES: MUSEOS DE BOGOTÁ-COLOMBIA

Angie Tatiana Beltrán Murcia - Jeffer Darío Buitrago Betancourt - Gilberto Stevan Moreno Mejía

en la Conferencia ASCOLFA 2015. Bogotá: ASCOLFA.

Bautista, M. (2012). El Museo del Oro. Un caso de gestión de patrimonio cultural. Cuaderno de Casos. Bogotá: Universidad EAN.

Bustos, y Rodríguez, (2009). Bogotá, una memoria viva. Alcaldía Mayor de Bogotá

Corral, Y. (2009). Validez y confiabilidad de los instrumentos de investigación para la recolección de datos. Revista Ciencias de la Educación, 19, p. 228-247.

Daza Corredor, A., Viloria Escobar, J., \& Miranda Terraza, L. (2018). De la responsabilidad social empresarial (RSE) a la creación de valor compartido (CVC): una reflexión crítica sobre los dos conceptos. Aglala, 9(1), 263-285. http://revistas.curnvirtual.edu.co/index.ph p/aglala/article/view/1193

Escobar, J. y Cuervo, Á. (2008). Validez de contenido y juicio de expertos: una aproximación a su utilización. Avances en Medición, 6 (1), p. 27-36.

Espitia, L. y Padilla, A. (2015). La accesibilidad de las personas con discapacidad física en Colombia: una problemática que va más allá de la simple consagración normativa. Estudios De Derecho, 72 (160), p.189216. Disponible en: https://doi.org/10.17533/udea.esde.v72n1 $\underline{60 \mathrm{a} 08}$

Fernández, M. y Moral, M. (2017). La gestión sostenible del patrimonio cultural bajo el enfoque de la accesibilidad. International Journal of Scientific Management and Tourism, 3 (3), p. 157-180.

Galicia, L., Balderrama, J. y Navarro, R. (2017). Validez de contenido por juicio de expertos: propuesta de una herramienta virtual. Apertura: Revista de Innovación Educativa, 9 (2), p. 42-53.
García, P. (2018). Buscando las fuentes de Bogotá. Recorrido patrimonial por el centro histórico de la ciudad (tesis de maestría). Universidad Nacional de Colombia.

Instituto Distrital de Turismo [IDT], (2012). Proyecto 0740: Bogotá, ciudad turística para el disfrute de todos. Disponible en: http://bogotaturismo.gov.co/sites/default/fi les/archivo/08/740_formulacion_proyecto .pdf

Martínez, R. y García, A. (2015). La accesibilidad como recurso turístico en sitios de turismo cultural religioso. International Journal of Scientific Management and Tourism, 2015, 1, p. 7-39.

Ministerio de Comercio, Industria y Turismo (2009). Política de Turismo Social: Hacia un turismo accesible e incluyente para todos los colombianos. Disponible:http://www.bogotaturismo.gov. co/sites/intranet.bogotaturismo.gov.co/file s/Politica\%20Turismo\%20Social.pdf

Ministerio de Cultura de Colombia (2020). Museo Santa Clara. Disponible en: http://www.museocolonial.gov.co/instituci on/historia/Paginas/default.aspx

Molina, M. Cànoves, G. (2010). Turismo accesible, turismo para todos: la situación en Cataluña y España. Cuadernos de Turismo, (25), p. 25-44. Disponible en: https://www.redalyc.org/articulo.oa?id=39 813352002

Museo Nacional de Colombia (2014). Colombia, territorio de museos. Diagnóstico del sector museal colombiano, año 2013. Programa de Fortalecimiento de Museos.

Organización Mundial del Turismo [OMT], (2014). Recomendaciones de la OMT por un turismo accesible para todos, OMT, Madrid. 
concept at museums in Jakarta. IOP: Conf. Series: Earth and Environmental Science, 126. DOI:10.1088/17551315/126/1/012061
Rojas, C. (2014). Museos y conflicto; la representación de la guerra en la museografía colombiana. Illapa. Revista del Instituto de Morolo Investigaciones Museológicas y Artísticas de la Universidad Ricardo Palma, 11, p. 123134.

Samboní, M. (Comp.) (2015). Manual de buenas prácticas de accesibilidad para museos: experiencias Museo de Arte Contemporáneo de Bogotá. Bogotá: Museo de Arte Contemporáneo.

Sánchez, J., Loarte, M. y Caisachana, D. (2020). Turismo accesible e inclusivo en el Ecuador, frente al turismo accesible en otros países. Universidad y Sociedad, 12(1), 225-231.

Sandoval, C. (2015). Aglomeración turística y desarrollo económico local: el caso de la localidad de La Candelaria (Bogotá, Colombia). Bogotá: Universidad de los Andes, Ediciones Uniandes.

Universidad Nacional de Colombia, Sede Bogotá [UN], Instituto Distrital de Turismo [IDT] y Alcaldía Local de Teusaquillo [ALT], (2011). Protocolos de servicio para el turismo accesible de turistas y visitantes jóvenes, adultos mayores y personas en situación de discapacidad. Disponible en: http://www.bogotaturismo.gov.co/sites/de fault/files/Adultos_Mayores.pdf

Vargas, S. (2016). Resemantizar la Independencia y pensar la ciudadanía: El proyecto de renovación del Museo de la Independencia Casa del Florero. En Anuario de Historia Regional y de las Fronteras, 21 (2). p. 75-100.

Wiastuti, R., Adiati, M. y Lestari, M. (2018). Implementation of accesible tourism 